
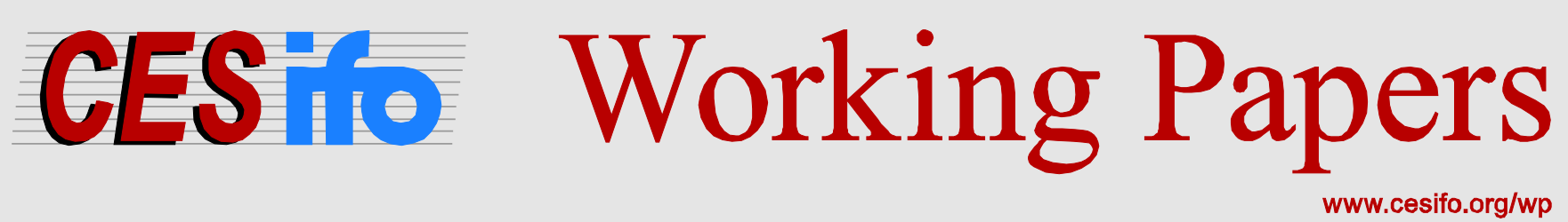

\title{
Taxation of Shareholder Income and the Cost of Capital in a Small Open Economy
}

\author{
Peter Birch Sørensen
}

\author{
CESIFO WORKING PAPER NO. 5091 \\ CATEgORY 1: Public FinANCE \\ NOVEMBER 2014
}
An electronic version of the paper may be downloaded
- from the SSRN website: Www.SSRN.com
- from the RePEc website: Www.RePEc.org
- from the CESifo website: www.CESifo-group.org/wp

\section{CESifo}




\title{
Taxation of Shareholder Income and the Cost of Capital in a Small Open Economy
}

\begin{abstract}
When companies finance their investment via the international markets for stocks and bonds, relief from domestic personal taxes on dividends and capital gains will not reduce the cost of capital. Some authors have shown that even for small domestic companies whose shares are not traded internationally, domestic shareholder tax relief will not necessarily reduce the cost of equity finance. This paper argues that, under realistic assumptions, domestic shareholder tax relief will in fact reduce the cost of capital for small firms. It also argues that a shareholder income tax on the equity premium with full loss offset will improve the allocation of risk in the economy.
\end{abstract}

JEL-Code: H200.

Keywords: double tax relief, cost of capital, dividend taxation.

Peter Birch Sørensen

University of Copenhagen

Department of Economics

Øster Farimagsgade 5

Denmark-1353 Copenhagen K

pbs@econ.ku.dk

November 2014 


\title{
TAXATION OF SHAREHOLDER INCOME AND THE COST OF CAPITAL IN A SMALL OPEN ECONOMY
}

\author{
Peter Birch Sørensen
}

\section{The problem: Does shareholder tax relief work in an open economy?}

Under a classical corporate tax system equity income is subject to corporate income tax, and in addition shareholders pay full personal income tax on their dividends and capital gains on shares in the company. In a closed economy such double taxation will drive the cost of capital for equity-financed corporate investment above the rate of return that would be required in the absence of tax.

Economic theory suggests that this distortion may be avoided if shareholders can deduct a risk-free after-tax rate of return from the base of the personal tax on dividends and capital gains. Provided the deduction and the corresponding tax relief is granted with certainty even when the realized return on shares is lower than the risk-free rate (and possibly negative), the present value of the rate-of-return allowance will equal the amount originally invested in the share. In principle, a shareholder income tax with a rate-of-return allowance (RRA) therefore works like a cash flow tax which is known to be neutral towards investment decisions. Not surprisingly, a shareholder income tax with an RRA (and full loss offset) is therefore also neutral in a closed economy, as shown by Sørensen (2005a).

In the closed economy such tax relief at the shareholder level works because it reduces the required pre-tax rate of return on shares. But in a small open economy with a stock market that is integrated in the world capital market, the required rate of return on domestic shares may be determined by the behaviour of foreign rather than domestic investors. In that case the required return on shares issued by domestic companies may not be affected by changes in domestic personal tax rules. On this basis Boadway and 
Bruce (1992) and Fuest and Huber (2000) argued that tax relief for domestic (resident) shareholders will fail to reduce the cost of corporate capital in a small open economy.

One objection to this argument is that, even in a small open economy, not all shares are traded internationally. Hence one might expect that tax relief for domestic shareholders will at least reduce the cost of capital for small closely-held companies controlled by one or a few domestic residents. Yet Apel and Södersten (1999) and Lindhe and Södersten (2012) found that even if one allows for the presence of such companies, a lower effective personal tax rate on domestic shareholder income will not necessarily lower the cost of capital for small domestic companies and may actually raise it. In particular, Lindhe and Södersten (2012) argue that the rate-of-return allowance introduced in Norway from 2006 may fail to reduce the required return on shares in small domestic companies. At the same time, Sørensen (2005b) has argued that the Norwegian shareholder income tax with a rate-of-return allowance may be approximately neutral not just in a closed economy, but also in the open-economy context. In other words, while the Norwegian shareholder income tax may not be able to neutralize the negative impact of the corporate income tax on the incentive for domestic real investment, it may generate additional government revenue at almost no additional social cost.

In this note I will show that the conclusion of Lindhe and Södersten (2012) as well as the conclusion drawn by Sørensen (2005b) may be derived from the same simple model of portfolio choice in a small open economy (essentially the model used by Lindhe and Södersten), albeit under different assumptions about parameter values. I will also argue that, under realistic assumptions, a rate-of-return allowance does reduce the cost of capital for small companies, thereby stimulating domestic investment, and I will present a simple formula that allows a quantitative estimate of the impact of the RRA on the cost of capital for these companies.

I do not take issue with the common view that double tax relief at the corporate rather than the personal level is a more effective means of stimulating domestic investment in a small open economy. ${ }^{1}$ I merely argue that tax relief for domestic personal shareholders will in fact reduce the required rate of return on investment in small domestic companies.

\footnotetext{
${ }^{1}$ See, e.g., Griffith, Hines and Sørensen (2010) for a broader discussion of the effects of taxation on investment incentives in an open economy.
} 
The rest of this note is organized as follows. Section 2 offers a brief formal restatement of the view that shareholder tax relief is wholly ineffective in a small open economy when the domestic stock market is fully integrated in the world stock market. Section 3 extends the analysis to a more realistic setting with non-traded as well as traded shares to illustrate why shareholder tax relief may lower the required return on non-traded shares. Section 4 introduces uncertainty explicitly into the analysis of portfolio choice and explains the assumptions needed to arrive at the conclusions drawn by Lindhe and Södersten (2012) and Sørensen (2005b), respectively. The section also presents a simple formula that can be used to quantify the impact of the RRA on the required pre-tax return on shares in small domestic companies. Section 5 sets up a simpler model of portfolio choice under uncertainty which is arguably more suitable for understanding the choices faced by a potential owner of a small closely-held company. From this model I derive an even simpler formula for the impact of a rate-of-return allowance on the cost of capital. Section 6 summarizes the main conclusions.

\section{When is shareholder tax relief ineffective? A simple illustra- tion}

Consider a small open economy where domestic financial investors may invest in riskfree bonds paying a safe after-tax interest rate $i$ or in risky shares yielding an expected return $\rho^{e}$ before personal tax. Suppose the domestic personal tax on shareholder income is residence-based and levied at an effective rate $t$, and let $V_{0}$ denote the total financial wealth of domestic investors. Assuming that bonds and shares are imperfect substitutes, we may then specify the total domestic demand for shares (denoted by $Q$ and valued at going market prices) as

$$
\begin{aligned}
Q & =Q\left(i, \rho^{e}(1-t), V_{0}\right), \\
Q_{i} \equiv \frac{\partial Q}{\partial i}<0, \quad Q_{\rho} & \equiv \frac{\partial Q}{\partial \rho^{e}(1-t)}>0, \quad 0<Q_{V} \equiv \frac{\partial Q}{\partial V_{0}}<1 .
\end{aligned}
$$

According to (2.1) a higher after-tax return on bonds will reduce the demand for shares by inducing investors to shift part of their portfolio into bonds, whereas a higher expected 
after-tax return on shares will stimulate the demand for them. Further, at given rates of return, a fraction $Q_{V}$ of any increase in initial wealth will be invested in shares.

Suppose further that all domestic bonds and shares are traded in fully integrated international capital markets. When the domestic economy is negligibly small relative to the world economy (and the domestic residence-based tax on interest income is held fixed), the rates of return $i$ and $\rho^{e}$ will then be exogenously determined by the behaviour of foreign investors, so a cut in the effective domestic shareholder income tax rate $t$ will not reduce the required pre-tax rate of return on domestic shares. Hence the government cannot reduce the cost of capital for domestic companies by offering dividend tax relief to domestic residents. According to (2.1) the only effect of a cut in $t$ will be to stimulate the domestic demand for shares, thereby increasing the proportion of domestic shares owned by domestic residents.

\section{When shareholder tax relief might work: a more realistic ex- ample}

Let us now consider a more realistic example where domestic investors may invest in three types of assets: risk-free bonds traded in the international capital market; risky shares in quoted (foreign and domestic) companies, likewise traded in the international capital market, and risky shares in unquoted domestic companies which are not traded internationally. We may reasonably assume that the two types of shares are imperfect substitutes with different risk characteristics, because the two kinds of firms will tend to predominate in different sectors of the economy, and because they have different ownership and governance structures. ${ }^{2}$ The demand for domestic unquoted shares $(D)$ will then be given by the asset demand function

$$
\begin{gathered}
D=D\left(i, \rho^{e}(1-t), r^{e}(1-t), V_{0}\right) \\
D_{i} \equiv \frac{\partial D}{\partial i}<0, \quad D_{\rho} \equiv \frac{\partial D}{\partial \rho^{e}(1-t)}<0, \quad D_{r} \equiv \frac{\partial D}{\partial r^{e}(1-t)}>0, \quad 0<D_{V} \equiv \frac{\partial D}{\partial V_{0}}<1
\end{gathered}
$$

\footnotetext{
${ }^{2}$ Hagen and Sørensen (1998) offer a detailed discussion of the different incentive structures and agency problems characteristic of different organizational forms.
} 
where $r^{e}$ is the expected pre-tax return on domestic unquoted shares, and $\rho^{e}$ is the expected pre-tax return on the quoted internationally traded shares. In a portfolio equilibrium, the demand for unquoted shares must equal the value $K$ of the shares issued by domestic unquoted companies:

$$
D=K
$$

Total investor wealth is the sum of the value of bondholdings $(B)$, the value of the holding of quoted shares $(Q)$, and the value of unquoted shares:

$$
V_{0}=B+Q+D
$$

Equation (3.3) implies that the partial derivatives of the asset demand functions with respect to $r^{e}(1-t)$ must satisfy the following adding-up constraint, where $B_{r} \equiv \partial B / \partial r^{e}(1-t)$ and $Q_{r} \equiv \partial Q / \partial r^{e}(1-t)$, and where the brackets indicate the expected signs of the derivatives:

$$
\stackrel{(-)}{B_{r}}+\stackrel{(-)}{Q_{r}}+\stackrel{(+)}{D_{r}}=0
$$

Under common assumptions regarding the properties of portfolio choice models, the partial derivatives will also satisfy the following symmetry condition: ${ }^{3}$

$$
Q_{r}=D_{\rho}
$$

From (3.4) and (3.5) it follows that

$$
\left.\stackrel{(-)}{B_{r}}+\stackrel{(-)}{D}\right) \stackrel{(+)}{D^{\prime}}=0 \quad \Longrightarrow \quad D_{r}>\left|D_{\rho}\right|
$$

In other words, a change in $r^{e}(1-t)$ has a stronger absolute effect on the demand for unquoted shares than a corresponding change in $\rho^{e}(1-t)$.

We may now investigate the effect of a change in the effective shareholder income tax rate $t$. In the short run considered here, we can take the initial values of $V_{0}$ and

\footnotetext{
${ }^{3}$ For example, Taylor and Clements (1983) set up a model of portfolio choice where financial assets are held by investors for the dual purposes of generating income and satisfying transactions requirements. Investors choose their portfolio so as to maximize their real after-tax income from investment, subject to a transactions technology in which the transactions (or liquidity) services of the assets are at a level determined by total real wealth. Taylor and Clements show that asset demands will then satisfy a symmetry constraint like (3.5).
} 
$K$ to be predetermined. ${ }^{4}$ In the small open economy, the rates of return $i$ and $\rho^{e}$ are exogenously given from abroad, but the pre-tax rate of return on domestic unquoted shares is endogenously determined. Thus we may find $r^{e}$ by combining (3.1) with the equilibrium condition (3.2), taking $K$ as given:

$$
D\left(i, \rho^{e}(1-t), r^{e}(1-t), V_{0}\right)-K=0
$$

By implicit differentiation of (3.7), we get:

$$
\frac{d r^{e}}{d t}=\frac{r^{e} D_{r}+\rho^{e} D_{\rho}}{D_{r}(1-t)} .
$$

In the benchmark case where the initial returns on the two types of shares are equal $\left(r^{e}=\rho^{e}\right)$, we see from (3.6) and (3.8) that domestic dividend tax relief (i.e., $\left.d t<0\right)$ will certainly lower the required pre-tax return on domestic unquoted shares, as one would expect. More generally, it follows from (3.6) and (3.8) that dividend tax relief will succeed in lowering the cost of capital for domestic unquoted companies unless the required return on traded shares exceeds the initial required return on non-traded shares by a sufficient amount.

This provides some basis for the belief that dividend tax relief for domestic residents will not be wholly ineffective as a stimulus to domestic investment in a small open economy. On the other hand, we cannot rule out that the expression for $d r^{e} / d t$ in (3.8) could be zero or negative. Let us therefore consider a portfolio model with more structure to identify the key parameters likely to determine the sign of $d r^{e} / d t$.

\section{Shareholder tax relief in a model with uncertainty}

To highlight how Lindhe and Södersten (2012) and Sørensen (2005b) arrive at their conclusions regarding the effects of shareholder tax relief, I will use a mean-variance

\footnotetext{
${ }^{4}$ We may justify this assumption by thinking in terms of a discrete-time model where stock prices for the current period are set at the end of the previous period. Right after share prices have been set, the government announces the shareholder income tax rate for the current period. Investors then adjust their expectations of the end-of-period share price (and hence $r^{e}$ ) in the light of the observed excess asset demand until the stock market clears and trades for the current period take place. Alternatively, we might assume that the tax rate is announced before the stock price is set so that an immediate capitalization effect occurs. In that scenario one can show that the expression for $d r^{e} / d t$ will be proportional to the expression stated in (3.8), so the qualitative conclusions in this section will still hold.
} 
model of portfolio choice which is essentially identical to the one used by Apel and Södersten (1999) and Lindhe and Södersten (2012). The model is a simplified version of the one set up by Sørensen (2005b), and it also makes a few innocent normalizations in the Apel-Lindhe-Södersten model to streamline the formal exposition.

Consider a representative domestic investor who invests a fraction $v_{\rho}$ of his initial wealth in internationally traded shares and a fraction $v_{r}$ of wealth in domestic unquoted (non-traded) shares. The remaining fraction of initial wealth is invested in risk-free internationally traded bonds yielding an after-tax rate of return $i$. To analyze the effect of a rate-of-return allowance (RRA) for personal shareholders like the one applied in Norwegian tax law, I will now assume that shareholders are allowed to deduct a fraction $\alpha$ of the risk-free net rate of return from the base for the shareholder income tax. If the realized pre-tax rates of return on traded and non-traded shares are $\rho$ and $r$, respectively, if the shareholder income tax rate is $\tau$, and if the tax system allows full loss offset, the realized after-tax returns will thus be $\rho-\tau(\rho-\alpha i)$ and $r-\tau(r-\alpha i)$. With an initial wealth level $V_{0}$, the investor's wealth at the end of the period $(V)$ will then be

$$
V=\left\{1+v_{\rho}[\rho-\tau(\rho-\alpha i)]+v_{r}[r-\tau(r-\alpha i)]+\left(1-v_{\rho}-v_{r}\right) i\right\} V_{0}
$$

Assume that the risky returns to the two types of shares follow a normal distribution and that the investor has a utility function $u(V)$ displaying constant absolute risk aversion. According to a well-known result (see, e.g., Silberberg and Suen (2001, p. 401)), maximization of the investor's expected utility is then equivalent to maximizing the meanvariance utility function

$$
U=E[V]-\frac{C}{2} \operatorname{var}[V]
$$

where $E[V] \equiv V^{e}$ is the expected level of wealth at the end of the period, $\operatorname{var}[V] \equiv$ $E\left[\left(V-V^{e}\right)^{2}\right]$ is the variance of terminal wealth, and $C$ is the constant coefficient of absolute risk aversion. Denoting expected returns by the superscript $e$, it follows from (4.1) that

$$
\begin{gathered}
E[V]=\left\{1+v_{\rho}\left[\rho^{e}-\tau\left(\rho^{e}-\alpha i\right)\right]+v_{r}\left[r^{e}-\tau\left(r^{e}-\alpha i\right)\right]+\left(1-v_{\rho}-v_{r}\right) i\right\} V_{0} \\
\operatorname{var}[V]=V_{0}^{2}(1-\tau)^{2}\left(v_{\rho}^{2} \sigma_{\rho}^{2}+v_{r}^{2} \sigma_{r}^{2}+2 v_{\rho} v_{r} \sigma_{\rho r}\right)
\end{gathered}
$$

where $\sigma_{j}^{2}$ is the variance of the return on asset $j$, and $\sigma_{\rho r}$ is the covariance between the returns on traded and non-traded shares. Given the expected rates of return and the risk 
characteristics of the three asset types, the investor chooses the portfolio shares $v_{\rho}$ and $v_{r}$ so as to maximize the utility function (4.2). Using (4.3) and (4.4), we find the first-order conditions for the solution to this problem to be

$$
\begin{aligned}
& \partial U / \partial v_{\rho}=0 \quad \Longrightarrow \quad \rho^{e}=i\left(\frac{1-\alpha \tau}{1-\tau}\right)+C V_{0}(1-\tau)\left(v_{\rho} \sigma_{\rho}^{2}+v_{r} \sigma_{\rho r}\right) \\
& \partial U / \partial v_{r}=0 \quad \Longrightarrow \quad r^{e}=i\left(\frac{1-\alpha \tau}{1-\tau}\right)+C V_{0}(1-\tau)\left(v_{r} \sigma_{r}^{2}+v_{\rho} \sigma_{\rho r}\right)
\end{aligned}
$$

We see that the required expected rates of return on shares are equal to the tax-adjusted risk-free rate of return, $i\left(\frac{1-\alpha \tau}{1-\tau}\right)$, plus a risk premium depending on the investor's degree of risk aversion $(C)$ and on the riskiness of the returns to the two asset types as well as on the covariance between the returns. In the small open economy the required pre-tax return on traded shares $\left(\rho^{e}\right)$ is given from abroad, as already noted. But how does the tax system affect the required return on domestic non-traded shares $\left(r^{e}\right)$ ? To investigate this, it is useful to start by solving (4.5) for $C V_{0}(1-\tau)$ and inserting the result into (4.6) to get

$$
r^{e}=i\left(\frac{1-\alpha \tau}{1-\tau}\right)+\widetilde{\beta}\left[\rho^{e}-i\left(\frac{1-\alpha \tau}{1-\tau}\right)\right], \quad \widetilde{\beta} \equiv \frac{v_{r} \sigma_{r}^{2}+v_{\rho} \sigma_{\rho r}}{v_{\rho} \sigma_{\rho}^{2}+v_{r} \sigma_{\rho r}}
$$

Now suppose the shareholder income tax grants a full deduction for the risk-free (aftertax) rate of return so that $\alpha=1$. It then follows from (4.7) that

$$
\lim _{v_{r} \rightarrow 0} r^{e}=i+\beta_{\rho}\left(\rho^{e}-i\right), \quad \beta_{\rho} \equiv \frac{\sigma_{\rho r}}{\sigma_{\rho}^{2}}
$$

We see that the tax rate has dropped out of (4.8). In other words, when unquoted shares only comprise a negligible fraction of total investor wealth $\left(v_{r} \rightarrow 0\right)$, a shareholder income tax with a full rate-of-return allowance (and full loss offset) will be roughly neutral. This is the basis for the claim made by Sørensen (2005b) that, in a small open economy with a well-developed capital market where the bulk of shares are traded internationally, a shareholder income tax with an RRA is probably not far from being neutral. ${ }^{5}$

But let us now focus on the case where $v_{r}$ is non-negligible, and let us investigate the basis for the claim made by Lindhe and Södersten (2012) that the RRA-system is likely to be an ineffective means of lowering the cost of capital for small domestic companies.

\footnotetext{
${ }^{5}$ Of course it is an empirical question whether the porftfolio share $v_{r}$ is sufficiently close to zero to warrant such a conclusion.
} 
We maintain the assumption that the initial asset prices and the total initial stock of wealth are predetermined (see the justification in footnote 4). Without loss of generality, we may normalize the initial stock prices at unity. We then have

$$
v_{\rho}=\frac{Q}{V_{0}}, \quad v_{r}=\frac{K}{V_{0}}
$$

where $Q$ is now the quantity of internationally traded shares, and $K$ is the predetermined quantity of shares in domestic unquoted companies. Using (4.9), we can then rewrite (4.5) and (4.6) as follows:

$$
\begin{aligned}
& \rho^{e}=i\left(\frac{1-\alpha \tau}{1-\tau}\right)+C(1-\tau)\left(Q \sigma_{\rho}^{2}+K \sigma_{\rho r}\right), \\
& r^{e}=i\left(\frac{1-\alpha \tau}{1-\tau}\right)+C(1-\tau)\left(K \sigma_{r}^{2}+Q \sigma_{\rho r}\right) .
\end{aligned}
$$

The endogenous variables in the short-run model (4.10) and (4.11) are $Q$ and $r^{e}$. Now solve (4.10) for $Q$ and use the definition of $\beta_{\rho}$ stated in (4.8):

$$
Q=\frac{\rho^{e}-i\left(\frac{1-\alpha \tau}{1-\tau}\right)}{C(1-\tau) \sigma_{\rho}^{2}}-\beta_{\rho} K
$$

Then insert (4.12) in (4.11) to obtain the following result, essentially equivalent to eq. (32) in Lindhe and Södersten (2012, p. 438):

$$
r^{e}=\beta_{\rho} \rho^{e}+\left(1-\beta_{\rho}\right) i\left(\frac{1-\alpha \tau}{1-\tau}\right)+C(1-\tau) K \sigma_{r}^{2}\left(1-\beta_{\rho} \beta_{r}\right), \quad \beta_{r} \equiv \frac{\sigma_{\rho r}}{\sigma_{r}^{2}} .
$$

From (4.13) we can derive the effect of increasing the rate-of-return allowance under the shareholder income tax:

$$
\frac{\partial r^{e}}{\partial \alpha}=-\frac{\left(1-\beta_{\rho}\right) i \tau}{1-\tau}
$$

According to (4.14) the effect on $r^{e}$ of changing the RRA is ambiguous, since it depends on the magnitude of the parameter $\beta_{\rho} \equiv \sigma_{\rho r} / \sigma_{\rho}^{2}$ which may be larger or smaller than 1 . Surprisingly, it thus seems that a more generous RRA may actually increase the required return on shares in unquoted companies. To understand why, note from (4.12) that a rise in $\alpha$ will induce the investor to increase his holdings of quoted shares. If $\beta_{\rho}$ is high, that is, if the return on unquoted shares correlates strongly with the return on quoted shares, the rise in $Q$ may increase the total risk in the investor's portfolio to such an extent that he will want to hold fewer unquoted shares in order to reduce his overall exposure to 
risk. With a given supply of unquoted shares, a lower demand for them requires a higher expected return on them to maintain market equilibrium.

According to this analysis the size of $\beta_{\rho}$ is crucial for the effect of the rate-of-return allowance. Lindhe and Södersten (2012) use Nordic stock market data for the period 1990-2010 to provide an empirical estimate for the magnitude of $\beta_{\rho}{ }^{6}$ They generally find that $\beta_{\rho}$ falls in the interval from roughly 0.7 to 1.0 , but they also note that in some subperiods $\beta_{\rho}$ has actually been slightly above 1.0. This is the basis for their claim that the RRA is an ineffective means of lowering the required pre-tax return on shares in small companies.

However, to arrive at their estimates for $\beta_{\rho}$, Lindhe and Södersten assume that the companies included in the so-called Small Cap index in the stock exchanges of the Nordic countries are representative of the small unquoted companies in our model. This assumption is hardly warranted. On average, the quoted companies in the Small Cap stock indices are likely to be larger and more integrated in the world economy than the typical small closely-held unquoted company. Larger firms tend to be more export-oriented, so one would expect that the Small Cap companies are on average more exposed to international business cycle conditions than the typical small domestic firm. Since the domestic and the international business cycle are rarely perfectly correlated, one would therefore expect a weaker correlation between the returns on quoted and unquoted shares than the correlation between the returns on the two types of quoted shares calculated by Lindhe and Södersten. Hence the estimates for $\beta_{\rho}$ provided by Lindhe and Södersten are likely to have an upward bias. Given that their estimates fall in the range of $0.7-1.0$, it therefore seems reasonable to assume that the "true" (model-consistent) value of $\beta_{\rho}$ is in fact smaller than 1. In that case it follows from (4.14) that a rate-of-return allowance will indeed reduce the cost of capital for small companies whose shares are not traded internationally.

We can use (4.14) to get a feel for the likely magnitude of the increase in the cost of capital for these firms if the Norwegian RRA were abolished. Under the current

\footnotetext{
${ }^{6}$ Note that $\beta_{\rho}$ is closely related to the "beta" familiar from the standard Capital Asset Pricing Model $(\mathrm{CAPM})$. The beta-parameter in the CAPM measures the correlation between the individual asset return and the return on all shares in the market portfolio. Our parameter $\beta_{\rho}$ measures the correlation between unquoted and quoted shares, with the latter representing the "market portfolio".
} 
Norwegian tax system, we have $\alpha=1$, implying that $\frac{d r^{e}}{d \alpha / \alpha}=\frac{d r^{e}}{d \alpha}$. Hence the expression on the right-hand side of (4.14) measures the increase in $r^{e}$ that would occur if the RRA were fully abolished, i.e., if $d \alpha / \alpha=-1$. Given the likely upward bias in the Lindhe-Södersten estimates for $\beta_{\rho}$, a reasonable "guesstimate" could be $\beta_{\rho}=0.5$, and a plausible value of the after-tax risk-free return could be $i=0.02$. Further, under the current Norwegian tax system we have $\tau=0.27$. With these parameter values (4.14) implies that the required return on shares in unquoted companies would increase by slightly less than 0.4 percentage points if the RRA were abolished.

\section{Towards a more realistic model of small firms}

On reflection, the above analysis probably understates the effect of eliminating the RRA, since the underlying model assumes that the controlling owners of small firms invest a substantial (or at least a non-negligible) proportion of their total wealth in shares quoted on the stock exchange. While this may sometimes be the case, it is probably more common for the owners of small firms to invest all or practically all of their equity wealth in their own company. One reason may be that, to establish a business firm of a viable size, a certain minimum amount of equity may be needed, and this may exhaust most of the entrepreneur's limited stock of wealth.

In other words, for the typical small business owner with a limited amount of total wealth, the relevant portfolio choice may boil down to deciding whether to invest (more) equity in one's own company or to invest in interest-bearing assets, possibly by paying off some private (non-business) debt. In that case the expression for the investor's endof-period wealth simplifies from (4.1) to

$$
V=\left\{1+v_{r}[r-\tau(r-\alpha i)]+\left(1-v_{r}\right) i\right\} V_{0}
$$

In this scenario maximization of the utility function (4.2) with respect to $v_{r}$ implies that

$$
r^{e}=i\left(\frac{1-\alpha \tau}{1-\tau}\right)+C(1-\tau) K \sigma_{r}^{2},
$$

where I have used the fact that $v_{r}=K / V_{0}$ (given that the initial stock price is normalized to unity). From (5.2) we see that

$$
\frac{\partial r^{e}}{\partial \alpha}=\frac{-\tau i}{1-\tau}<0
$$


In this more realistic setting it follows from (5.3) that a more generous rate-of-return allowance will unambiguously reduce the required rate of return on equity-financed investment in small firms. Starting from a situation where $\alpha=1$, and given the previous parameter values $(i=0.02$ and $\tau=0.27)$, it also follows from (5.3) that a complete elimination of the RRA would increase the required return by about 0.75 percentage points. This is a significant increase in the cost of capital.

Under a tax system with a full RRA ( $\alpha=1)$, eq. (5.2) yields

$$
r^{e}=i+C(1-\tau) K \sigma_{r}^{2}
$$

Compared to a situation with no shareholder income tax $(\tau=0)$, we see from (5.4) that the tax actually reduces the required return on equity-financed investment, given the underlying assumption of full loss offset. This is consistent with the finding of Sandmo $(1977,1989)$ that a tax on the equity premium $(r-i)$ with full loss offset will stimulate the demand for risky assets, because the government effectively participates as a sleeping partner in all equity investments, bearing a fraction of the risk equal to the tax rate. In this way the shareholder income tax with an RRA tends to compensate for the lacking diversification of risk when the owners of small firms "put all of their eggs in one basket" by investing all of their equity in their own company.

The (approximate) neutrality result in (4.8) assumed that investor portfolios are fully diversified. The result in (5.4) represents the opposite pole where share portfolios are not diversified at all. For the owners of small companies, this probably comes closer to the truth. Eq. (5.4) clearly suggests that a Norwegian-type shareholder income tax with a rate-of-return allowance is not neutral. However, it also suggests that - to the extent that taxpayers are actually able to offset their losses - the tax may in fact improve efficiency by contributing to a better allocation of risk across the economy.

\section{Conclusions}

When companies finance their investment via the international markets for stocks and bonds, relief from domestic personal taxes on dividends and capital gains will not reduce the cost of capital. Some authors have argued that even for small domestic companies whose shares are not traded internationally, domestic shareholder tax relief will not reduce 
the cost of equity finance. In particular, Lindhe and Södersten (2012) have argued that a rate-of-return allowance for domestic personal shareholders is an ineffective means of reducing the cost of capital for small domestic firms. However, this conclusion seems to be based on an upward-biased estimate of the correlation between the returns on equity in small and large firms. Under realistic assumptions, a rate-of-return allowance is likely to reduce the cost of equity capital for small firms, probably by between $\frac{1}{2}$ and one percentage point per annum. There is also reason to believe that a shareholder income tax on the equity premium with full loss offset will improve the allocation of risk in the economy. 


\section{References}

Apel, M. and J. Södersten (1999). Personal taxation and investment incentives in a small open economy. International Tax and Public Finance 6, 79-88.

Boadway, R. and N. Bruce (1992). Problems with integrating corporate and personal income taxes in an open economy. Journal of Public Economics 48, 39-66.

Fuest, C. and B. Huber (2000). Can corporate-personal tax integration survive in open economies? FinanzArchiv 57, 514-24.

Griffith, R., J.R. Hines and P.B. Sørensen (2010). International capital taxation. Chapter 10 in The Mirrlees Review: Dimensions of Tax Design, Institute for Fiscal Studies, Oxford University Press.

Hagen, K. P. and P. B. Sørensen (1998). Taxation of income from small businesses: taxation principles and tax reforms in the Nordic countries. In P. B. Sørensen (ed.), Tax Policy in the Nordic Countries, Macmillan Press.

Lindhe, T. and J. Södersten (2012). The Norwegian shareholder tax reconsidered. International Tax and Public Finance 19, 424-441.

Sandmo, A. (1977). Portfolio theory, asset demand and taxation: Comparative statics with many assets. Review of Economic Studies 44, 369-79.

Sandmo, A. 1989. Differential taxation and the encouragement of risk taking. Economics Letters 31, 55-59.

Silberberg, E. and W. Suen (2001). The Structure of Economics - A Mathematical Analysis. Third Edition, McGraw-Hill.

Sørensen, P.B. (2005a). Neutral taxation of shareholder income. International Tax and Public Finance 12, 777-801.

Sørensen, P.B. (2005b). Taxation of shareholder income and the cost of capital in an open economy: theory and applications to the Nordic countries. Danish Journal of Economics (Nationaløkonomisk Tidsskrift) 143, 433-447. 
Taylor, J.C. and K.W. Clements (1983). A simple portfolio allocation model of financial wealth. European Economic Review 23, 241-251. 